\title{
Estimation of the strength of Nubian sandstone formation from point load test index and other simple parameters
}

\author{
Abdul Karim M. Zein ${ }^{1}$ and Mutasim A. Sandal ${ }^{2}$ \\ ${ }^{1}$ Building and Road Research Institute, University of Khartoum, Khartoum, Sudan \\ ${ }^{2}$ General Administration for Buildings, Ministry of Physical Planning, Khartoum State Khartoum, Sudan
}

\begin{abstract}
This study investigates the correlation of the uniaxial compressive strength (UCS) and the point load test (PLT) index $\mathrm{I}_{\mathrm{s}(50)}$, bulk density, water absorption and the RQD properties of the Sudanese Nubian sandstone formation. The UCS being is the rock property needed in engineering practice but its determination is tedious, time consuming and expensive. Alternatively, the UCS may be indirectly evaluated through establishing relationships with rock parameters which are easier, cheaper and more convenient to determine in the laboratory or in the field. An extensive laboratory testing was executed to determine the above rock properties for many NSF samples taken from Khartoum State and other areas. Statistical analysis was performed on the test data and a reliable linear regression equation has been developed with a UCS to PLT $\mathrm{I}_{\mathrm{s}(50)}$ conversion factor of 10.18 and may be applied to estimate the strength of the Sudanese sandstone formation. The developed correlation is in good agreement with few of the many methods published for similar rock types which indicates that large errors may result in from applying an inappropriate UCS prediction method. Thus, it is important to establish separate correlations or validate published correlations to check their suitability for a specific rock types and local geologies. Useful correlation relationships of reasonable accuracy were also established for rough estimation of the UCS from the bulk density, water absorption and the RQD properties of the Nubian sandstone formation. Keywords: Nubian sandstone formation, UCS, Point load index $\mathrm{I}_{\mathrm{s}(50)}$, Bulk Density, absorption, RQD.
\end{abstract}

\section{Introduction}

Evaluation of the shear strength characteristics of rocks is an important aspect in most geotechnical investigations related to engineering problems. Rock strength is normally evaluated in terms of the uniaxial compressive strength (UCS) which can be directly and accurately determined from laboratory testing. However retrieval of high quality samples is a prerequisite for testing which is often difficult to obtain for weak and highly weathered rocks and the test is time-consuming and expensive. Alternatively, the UCS may be indirectly estimated from the results of point load test (PLT) or other rock properties. The PLT test can be carried out on irregular shaped specimens and the equipment can be easily transported to the field.

Many empirical methods have been proposed by researchers from different countries to estimate the UCS from the PLT strength Index $I_{s(50)}$. However, the reliability of these relationships depends on the type, location and degree of weathering of rocks.
To the authors knowledge there is no reported research on how the UCS and the PLT strength index $\mathrm{I}_{\mathrm{s}(50)}$ are related to each other for the Sudanese rock types. The objective of this study is to establish the correlation between the two strength parameters for the Nubian sandstone formation which constitute a main geological feature on which many important structures are founded. The study also investigates the variations of the UCS with the bulk density, water absorption and rock quality designation (RQD) for the same rock formation.

\section{Rock strength parameters}

The UCS is often used in engineering practice for different applications such as the design of foundations and the stability of rock slopes. The test is typically determined as specified by the ASTM 
standard D7012-04 [1] from axial loading of unconfined cylindrical rock specimens of flat, smooth parallel ends with a length to width ratio of 2 to 2.5 .

The PLT is considered as an attractive indirect substitute to the UCS as it can provide similar data faster and at a lower cost. The ASTM gives a clear justification for the use of the PLT [2]. The test is especially useful when core specimens cannot be extracted from fractured or weathered rock masses. The PLT can be easily performed in the field or the laboratory on samples in the form of cores, blocks or irregular specimens with different diameters which require less or no preparation.

Other rock strength related properties include the "Rock Quality Designation, RQD", bulk density and water absorption. The RQD provides a basis for making preliminary decisions with respect to required depths of excavation for structures foundations. The above properties also can serve to identify potential problems related to bearing capacity, settlement, erosion, or sliding in rock foundations.

\subsection{Correlation of UCS and PLT $I_{s(50)}$ index}

Many authors have developed empirical relationships between the UCS and the PLT $\mathrm{I}_{\mathrm{s}(50)}$ with a conversion factor " $k$ " expressed by the following linear equation:

$U C S=k I_{S(50)}$

It has been shown that the factor $k$ is not constant but is rock type dependent; thus, it is important to establish separate correlations for specific rock types and local geologies.

The earliest and most widely used correlation equations were proposed by Broch and Franklin [3] and Bieniawki [4] with a $\mathrm{k}$ value of 24 based on data pertaining to different rock types. Since then, many equations have been formulated either for different types of rocks or for local formations. Examples of some of the available UCS-I $\mathrm{I}_{\mathrm{s}(50)}$ correlation relationships are listed in Table 1 with the details given in the corresponding reference. As may be noted from Table 1 , most of the UCS-I $\mathrm{I}_{\mathrm{s}(50)}$ equations are linear but some equations are linear with a nonzero intercept or nonlinear in the forms of power or exponential equations. The conversion factor of linear equations varies between 6 and 25 which clearly indicates that using an inappropriate correlation equation may result in erroneous evaluation of the UCS by several times the $\mathrm{I}_{\mathrm{s}(50)}$ value.

\section{Nubian sandstone formation}

In Sudan, the term "Nubian Formations (NF)" refers to the cretaceous continental sediments composed of sandstone, mudstone siltstone, conglomerates and pebbles. They are either exposed or overlain by recent quaternary formations and extend between latitude $22^{\circ}$ north and $10^{\circ}$ south. It constitutes about $45 \%$ of the total area of Sudan distributed in the northern, central western and eastern parts as depicted in Fig. 1.

Table 1 Examples of published UCS-I $\mathrm{I}_{(50)}$ equations

\begin{tabular}{|c|c|c|}
\hline Correlation equation & Reference name and No. & \\
\hline $\mathrm{UCS}=23.9 \mathrm{I}_{\mathrm{s}(50)}$ & Bieniawki (1975) & [4] \\
\hline $\mathrm{UCS}=18.7 \mathrm{I}_{\mathrm{s}(50)}-13.2$ & Singh (1981) & [5] \\
\hline $\mathrm{UCS}=14 \mathrm{I}_{\mathrm{s}(50)}$ & Foster (1985) & [6] \\
\hline $\mathrm{UCS}=18 \mathrm{I}_{\mathrm{s}(50)}$ & Das (1985) & [7] \\
\hline $\mathrm{UCS}=24.8 \mathrm{I}_{\mathrm{s}(50)}$ & Hawkins \& Oliver (1986) & [8] \\
\hline $\mathrm{UCS}=17.4 \mathrm{I}_{\mathrm{s}(50)}$ & Vallejo et al (1989) & [9] \\
\hline $\mathrm{UCS}=19 \mathrm{I}_{\mathrm{s}(50)}+12.7$ & Ulusay et al (1994) & [10] \\
\hline $\mathrm{UCS}=24 \mathrm{I}_{\mathrm{s}(50)}$ & Smith (1997) & [11] \\
\hline $\mathrm{UCS}=20.6 \mathrm{I} s(50)$ & Rusnak and Mack (1999) & [12] \\
\hline $\begin{array}{l}\mathrm{UCS}=3.86\left(\mathrm{I}_{\mathrm{s}(50)}\right)^{2} \\
+3.86 \mathrm{I}_{\mathrm{s}(50)}\end{array}$ & Quane and Russel (2003) & [13] \\
\hline $\mathrm{UCS}=7.31\left(\mathrm{I}_{\mathrm{s}(50)}\right)^{1.71}$ & $\begin{array}{l}\text { Tsiamaos \& Sabatakkis (2 } \\
{[14]}\end{array}$ & 2004) \\
\hline $\mathrm{UCS}=23 \mathrm{I}_{\mathrm{s}(50)}$ & Koukis et al (2007) & [15] \\
\hline $\mathrm{UCS}=6.5\left(\mathrm{I}_{\mathrm{s}(50)}\right)^{1.8}$ & Koukis et al (2007) & [15] \\
\hline $\mathrm{UCS}=11.076 \mathrm{I}_{\mathrm{s}(50)}$ & Akram and Baker (2007) & [16] \\
\hline $\mathrm{UCS}=6.21 \mathrm{I}_{\mathrm{s}(50)}$ & Elkateb (2009) & [17] \\
\hline $\mathrm{UCS}=21.9 \mathrm{I}_{\mathrm{s}(50)}$ & Singh et al (2012) & [18] \\
\hline $\mathrm{UCS}=17.6 \mathrm{I}_{\mathrm{s}(50)}-56.4$ & Singh et al (2012) & [18] \\
\hline $\mathrm{UCS}=5.68\left(\mathrm{I}_{\mathrm{s}(50)}\right)^{0.5}$ & Salah et al (2014) & [19] \\
\hline
\end{tabular}

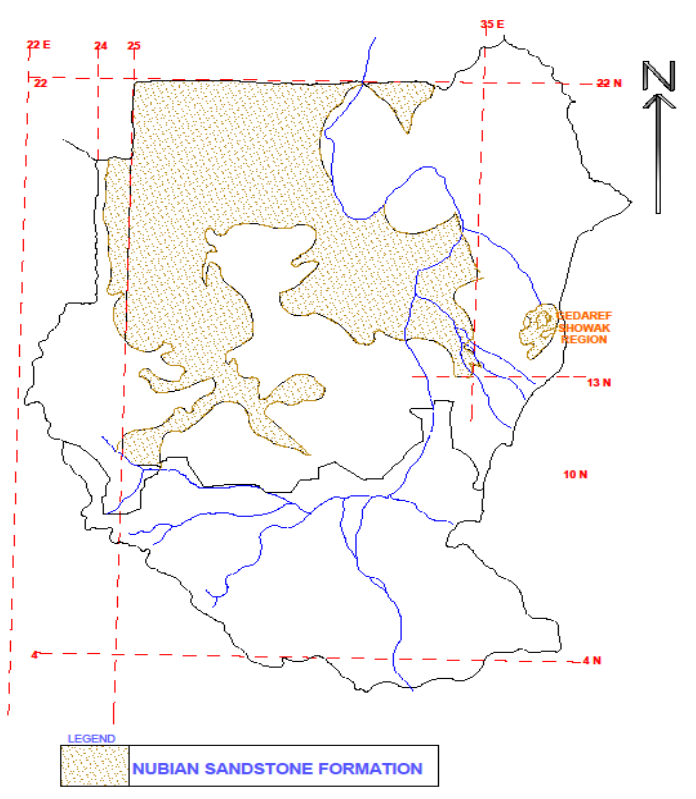

Fig. 1 Distribution of Nubian formation in Sudan

Geologically, the NF uncomfortably rests in Khartoum State on the basement complex with thickness varying between 120 and $420 \mathrm{~m}$ and is overlain by 7 to $25 \mathrm{~m}$ thick Tertiary or Quaternary 
deposits [20]. A number of hypotheses have been advocated about the types of depositional conditions by which the NF has been formed e.g. aeolian, deltaic, estuarine and marine types. Petro-graphic investigations results showed that the NF are essentially comprised of fine to medium sized quartz and rock fragments with an association of opaque minerals including chlorite, crinite and muscovite. Adherence between matrix and grains are weak and therefore the formation can easily be disintegrated. The results of a previous study showed that the NF is jointed, cracked and suffer facies changes and strength characteristics of weak rock and is characterized by variations in color. The sandstone is principally composed of angular to sub-angular quartz of variable sizes floating in a matrix of fine material with kaolin as the basic cementing material [21].

The need for undertaking this study stems from the fact that several important heavy structures such as multi-span bridges across major rivers and high rise buildings, dams, large water front structures pump stations are founded on the NF in Sudan.

\section{Research methodology}

This study is based on the results of laboratory tests performed on NF sandstone samples taken from different sites of large bridge projects and high rise building towers in Khartoum State and some other parts of Sudan. The bridge sites covered included $\mathrm{Al}$ Dabasin and New White Nile bridges on the White Nile, Al Manshiya, Khartoum-Tuti Island, Tuti Island-Khartoum Bahri, Soba, and Almek Nimer bridges on the Blue Nile and Alhalfaya bridge on the main River Nile.

Representative NF sandstone core samples were taken from boreholes drilled to depths reaching $50 \mathrm{~m}$ below ground elevations. After the sorting and visual examination of rock samples obtained from the boreholes, the RQD was determined then they were cut, trimmed and lapped to standard sizes. Preparation of core specimens and the testing was conducted in accordance to standard methods adopted by the ASTM [1] and the ISRM [22].

The UCS test was performed on sandstone cores with length to diameter ratio L/D more than one. The cores were stressed to fracture, at a very slow rate using a $1500 \mathrm{kN}$ compression machine (Fig. 2). The PLT was performed by loading cores against two pointed platens until failure occurred using the apparatus shown in Fig. 3. Specimens having diameters of $80 \mathrm{~mm}, 45 \mathrm{~mm}$ and $37 \mathrm{~mm}$ were tested and corrections were applied to calculate the index $\mathrm{I}_{\mathrm{s}(50)}$ using the equation:

$I_{S(50)}=\left(D_{e} / 50\right)^{0.45} P_{u} / D_{e}^{2}$

$P_{u}$ is the failure load and $D_{e}$ is the effective diameter of the core specimen tested.

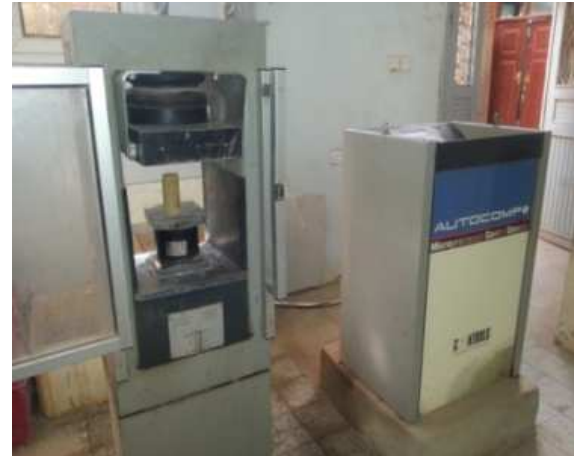

Fig. 2 UCS test apparatus used

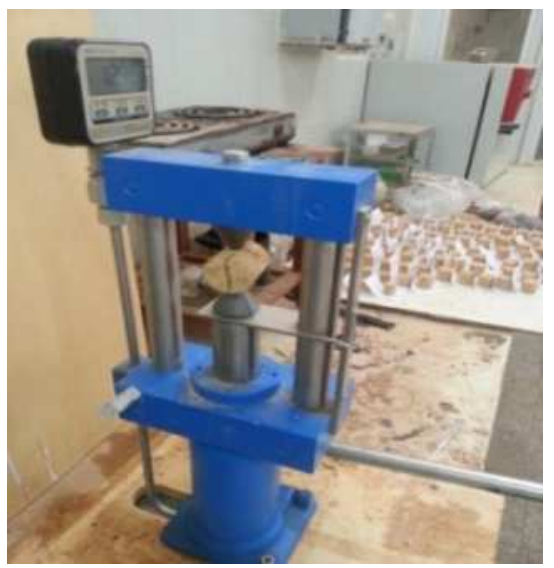

Fig. 3 Point load test apparatus used

The rock core specimens were trimmed to a regular shape of known volumes, weighed and used in the determination of natural bulk density. Water Absorption of the rock expressed in terms of the degree to which water is absorbed by the core samples was determined according to ASTM D6473-15 method [23] and expressed as a percentage of specimen dry mass.

Table 2 summarizes simple statistical data on the numbers of NF sandstone samples tested and the results of UCS, PLT, RQD, bulk density and water absorption results determined from performing the different test series.

Table 2 Statistical data of the various test results

\begin{tabular}{|l|c|c|c|c|}
\hline \multirow{2}{*}{$\begin{array}{c}\text { Test } \\
\text { Type }\end{array}$} & \multirow{2}{*}{$\begin{array}{c}\text { Data } \\
\text { Size }\end{array}$} & \multicolumn{3}{|c|}{ Statistical Data } \\
\cline { 3 - 5 } & & Range & Mean & $\begin{array}{c}\text { Std. } \\
\text { Dev. }\end{array}$ \\
\hline UCS $(\mathrm{MPa})$ & 369 & $0.17-35.88$ & 6.65 & 6.15 \\
\hline $\mathrm{I}_{\mathrm{s}(50)}(\mathrm{MPa})$ & 141 & $0.025-3.66$ & 0.64 & 0.54 \\
\hline$\gamma_{\mathrm{b}}\left(\mathrm{kN} / \mathrm{m}^{3}\right)$ & 239 & $0.83-3.54$ & 1.89 & 0.25 \\
\hline $\mathrm{A}_{\mathrm{b}}(\%)$ & 203 & $2.6-19.7$ & 12.4 & 3.3 \\
\hline $\mathrm{RQD}(\%)$ & 204 & $0-100$ & 46.63 & 25.2 \\
\hline
\end{tabular}




\section{Discussion of test results}

\subsection{General}

The results determined from testing of many sandstone samples were analyzed to establish the correlation between UCS and the PLT $\mathrm{I}_{\mathrm{s}(50)}$ using the statistical regression method. The relationships between the UCS, the bulk density, water absorption and the RQD of the sandstone were also studied using data from different test series.

For the core samples tested the UCS values varied from 0.57 to $18.0 \mathrm{MPa}$ and thus the formation may be classified as a rock of low strength. The above UCS values range is consistent with those exhibited in previous investigations carried out Greater Khartoum area. UCS values varying from 0.263 to $17.0 \mathrm{MPa}$ were reported at the sites of several engineering structures founded in the same rock formation [24]. The values of the strength index $\mathrm{I}_{\mathrm{s}(50)}$ determined from point load tests performed on 141 sandstone samples varied from 0.025 to $1.5 \mathrm{MPa}$ and thus the formation may be classified as of extremely low to high shear strength.

Relatively high and odd UCS and $\mathrm{I}_{\mathrm{s}(50)}$ values of about 36 and $3.5 \mathrm{MPa}$ respectively were revealed from testing two sandstone samples indicating that they represent a formation of moderate to very high strength. It is believed that the low UCS and $\mathrm{I}_{\mathrm{s}(50)}$ values determined for $99.5 \%$ of the samples tested are pertinent to the locally predominant sandstone type with kaolin as the basic cementing material. On the other hand, the two specimens with much higher UCS and $\mathrm{I}_{\mathrm{s}(50)}$ values seem to represent sandstone pockets cemented by ferrous oxide or mixed with gravel.

Statistical analysis was performed to establish mathematical models describing the best correlation relationship of the UCS with the $\mathrm{I}_{\mathrm{s}(50)}$ index, bulk density, water absorption and the RQD of sandstone samples as discussed below.

\subsection{Correlation of the UCS and $I_{s(50)}$}

To perform regression analysis the test data is normally plotted on a graph which allows visualization of the relationship trends prior to running data analysis. Different curve fitting relationships can be used to analyze the relationship between the dependent and independent variables. The curve fitting produces a measure of variability known as the coefficient of determination $\left(\mathrm{R}^{2}\right)$ on one variable that can be accounted for by variability on the other. Once the regression equations and the associated $\mathrm{R}^{2}$ values are determined the most appropriate curve fit which gives the highest $\mathrm{R}^{2}$ value is decided.

To establish the relationship between the UCS and PLT $I_{s(50)}$ index of the NF sandstone the data pertaining to 141 sample pairs were plotted as shown in Fig. 4.

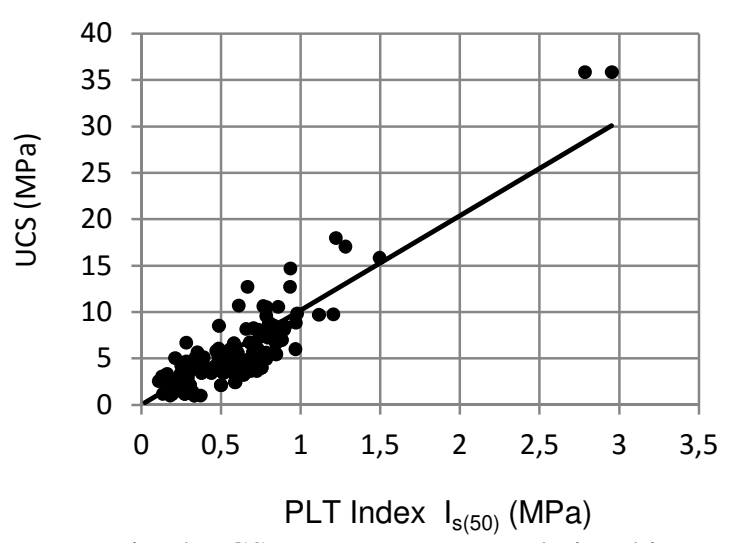

Fig. 4 UCS versus PLT $I_{\mathrm{s}(50)}$ relationship

Regression analysis was performed assuming different mathematical models but the following linear equation was found to give the best-fit correlation of the UCS with the $\mathrm{I}_{\mathrm{s}(50)}$ index:

$U C S=10.18 I_{S(50)}$

A determination coefficient $\mathrm{R}^{2}=0.81$ was yielded from data analysis indicating that the correlation of the two rock parameters is highly reliable.

The UCS to $\mathrm{I}_{\mathrm{s}(50)}$ conversion factor of 10.18 in equation 3 falls well within the range reported in other countries but it is lower than most of values given in the formulae listed in Table 1 for different sandstone rocks. The 10.18 factor value derived for $\mathrm{NF}$ sandstones varies from $45 \%$ to $180 \%$ respectively when compared to the highest and lowest values proposed in the published linear equations of Table 1. The variability in the UCS-I $\mathrm{I}_{\mathrm{s}(50)}$ relationship may be attributed to the intrinsic variability in the physical and mechanical properties of rocks due to their heterogeneous nature [25] as well as their nature and degree of weathering. In addition, part of the variability can be attributed to the inaccuracies in the determination of the true UCS and the $I_{s(50)}$ and the real test type differences. This indicates that a random application of published correlation equations may result in large errors leading to unrealistic prediction of UCS. Such large errors in estimating rock strength from the PLT or other test results are not acceptable and emphasize the necessity of establishing local correlation methods.

The UCS-I $\mathrm{I}_{\mathrm{s}(50)}$ correlation equation developed in this study is in close agreement with that proposed by Akram and Baker [15] for two sandstone types from Pakistan. A good agreement was also revealed between the correlation obtained in this study and the linear and power formulae by Quane and Russel [13] and Salah et al [19] for weak sandstone rocks with UCS and $\mathrm{I}_{\mathrm{s}(50)}$ values lower than 20 and $1.5 \mathrm{MPa}$ respectively as graphically illustrated in Fig. 5. 


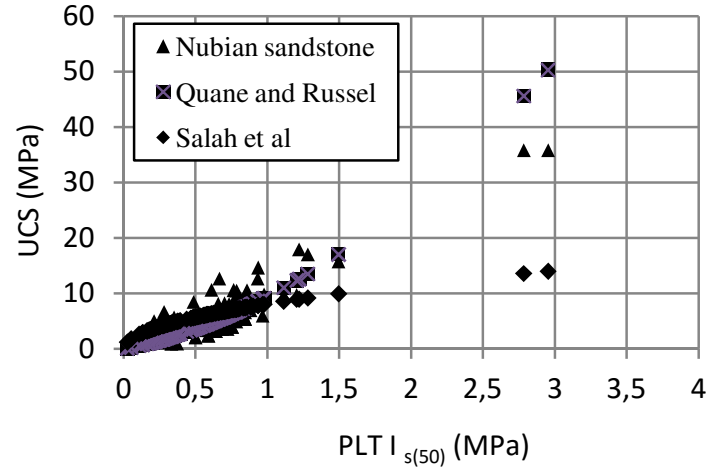

Fig, 5 Comparison of developed UCS-I $\mathrm{I}_{\mathrm{s}(50)}$ equation with previous correlation methods

Equation 3 may be used estimate the UCS of the Sudanese Nubian sandstone formations from known values of the PLT $I_{s(50)}$ index. Though a high $R^{2}$ value was yielded from data analysis, the developed relationship accuracy can be further improved as more results are made available from future research works.

\subsection{Variations of UCS with bulk density, water absorption and RQD parameters}

The UCS and bulk density $\left(\gamma_{\mathrm{b}}\right)$ of the NF sandstone samples were plotted against each other in Fig. 6 which shows that the UCS increases with $\gamma_{\mathrm{b}}$ in a linear fashion. A sound relationship with an $R^{2}=0.702$ was developed from regression analysis of data pertaining to 153 sample pairs as:

$\operatorname{UCS}(M N)=26.1 \gamma_{b}\left(\mathrm{kN} / \mathrm{m}^{3}\right)-41.68$

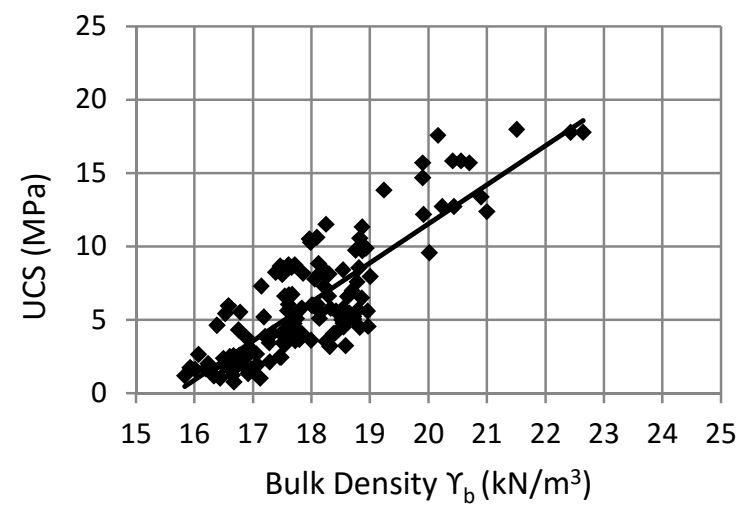

Fig. 6: Plot of UCS against bulk density

Similarly, the rock strength and the degree of water absorption $\left(\mathrm{A}_{b}\right)$ by the sandstone material were plotted for as shown in Fig 7 for 150 data points. The figure indicates an inverse linear relationship trend with UCS increasing as $A_{b}$ is decreasing.

The best-fit line equation given below was established to estimate UCS from $A_{b}$ with a reasonable degree of accuracy $\left(R^{2}=0.726\right)$ :

$U C S(M P a)=22.76-1.266 A_{b}(\%)$

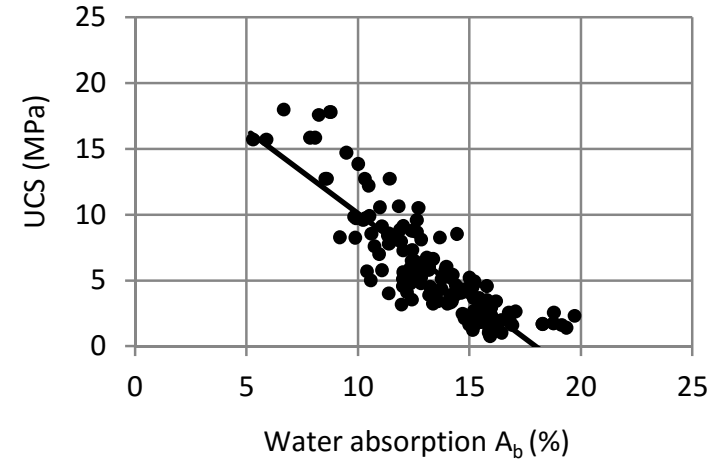

Fig. 7: Plot of UCS against water absorption

A less reliable but perhaps more practically useful correlation was established between UCS and RQD of the NF sandstone using the data points plotted in Fig. 8 which indicates that the two variables increase with each other. The best fit correlation equation given below was established from regression analysis $\left(\mathrm{R}^{2}=\right.$ 0.511 ):

$$
U C S(M P a)=0.092 R Q D(\%)
$$

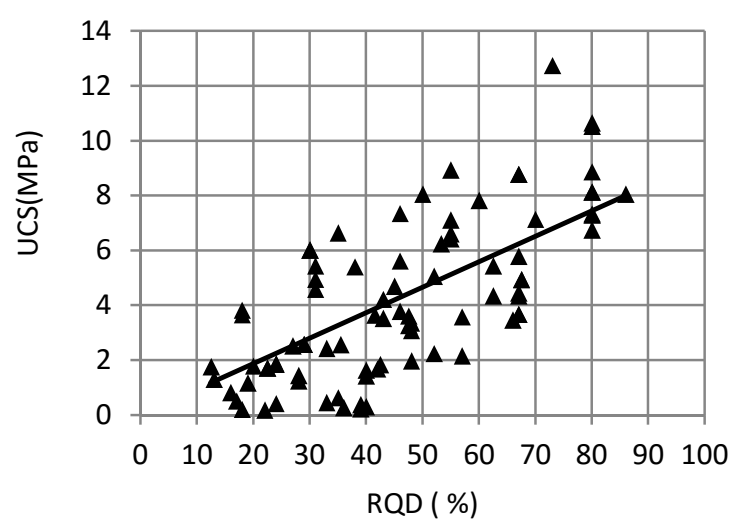

Fig. 8: Plot of UCS against RQD

\section{Conclusions}

Direct laboratory testing is the most reliable method for the determining the UCS of rocks; however it is often difficult to obtain the quality of specimens required for testing in weak rocks such as NF sandstones. Moreover, the UCS test is tedious, timeconsuming and expensive.

The point load test (PLT) represents an alternative for indirect evaluation of the UCS through a correlation with the strength index $\mathrm{I}_{\mathrm{s}(50)}$. The PLT requires less or no sample preparation and can be easily performed in the laboratory and field using less sophisticated equipment.

Many UCS-I $\mathrm{I}_{\mathrm{s}(50)}$ correlation equations have been proposed worldwide but they are material type and site dependent. Application of such relationships for a different material can result in large errors in rock strength prediction.

A comprehensive study was undertaken to determine the UCS, PLT, bulk density, water 
absorption and the RQD properties of many Sudanese NF sandstone samples collected from sites wherein they are most predominant.

Analysis the test results was performed using regression method and a reliable linear equation with a UCS to $I_{s(50)}$ factor of 10.18 was developed for the Sudanese Nubian sandstone formation. Similarly, reasonably accurate relationships have been established to estimate the UCS of the NF sandstone from bulk density, water absorption and the RQD parameters. The relationships developed may be used by local engineers to roughly estimate the UCS of the NF sandstone but with some care until they are confirmed or more refined by future research works.

\section{References}

1. ASTM International. D 7012-04 Standard test method for compressive strength and elastic modulus of intact rock core specimens under varying states of stress and temperatures, West Conshohocken, USA (2009).

2. ASTM International D 5731-05 Standard test method for determination of the point load index of Rock, West Conshohocken. U.S.A (2009)..

3. Broch, E., Franklin, J.A.. The point load test. Int. J. Rock Mechanics, Mining and Science 9, 669697(1972)

4. Bieniawski ZT. The point-load test in geotechnical practice. Engineering Geology; 9(1):1e11 (1975).

5. Singh, D. P.: Determination of some engineering properties of weak rocks, Proc. Int. Symposium on Weak Rock, Tokyo, 21-24. 32) (1981)

6. Forster, I. R. The influence of core sample geometry on the axial point-load test, Int. J. of Rock Mechanics and Mining Sciences and Geomechanical Abstract, 20 (6), 291-295(1983).

7. Das, B. M.: Evaluation of the point load strength for soft rock classification, Proc., $4^{\text {th }}$ Int. conf. on ground control in mining, Morgantown, WV, 220226, (1985).

8. Hawkins, A. B., Olver, J. A. G.,: Point load tests: correlation factor and contractual use. In: Hawkins, A.B. (Ed.), Site Investigation Practice: Assessing BS 5930, Geological Society, London, 269-271, (1986)

9. Vallejo, L. E., Welsh, R. A., Robinson, M. K.: Correlation between unconfined compressive and point load strength for Appalachian rocks, Proc. $30^{\text {th }}$ US Symposium on Rock Mechanics, Morgantown, 461-468, (1989)

10. Ulusay, R., Tureli, K., and Ider, M. H. Prediction of Engineering Properties of a selected Litharenite Sandstone from its Petrographic Characteristics using Correlation and Multivariate Statistical Techniques, Engineering Geology, 38(2), 135-157. 36), (1994)

11. Smith, H. J. The point load test for weak rock in dredging applications, In. J. of Rock Mechanics and Mining Sciences, 34, 295, 3-4, (1997).
12. Rusnak, J. A., Mark, CUsing the point load test to determine the uniaxial compressive strength of coal measure rock, Proc. $19^{\text {th }}$ Int. conf. on ground control in mining, 30, 362-371, (1999).

13. Quane S.L., Russel, J.K. Rock strength as a metric of welding intensity in pyroclastic deposits Eur. J. Mineral., 15, 855-864. 8. T. N (2003).

14. Tsiambaos G, Sabatakakis N. Considerations on strength of intact sedimentary rocks. J. Engineering Geology; 72(3e4): $261 \mathrm{e} 73$ (2004).

15. Koukis G. t, Sabatakakis N. t, and Papanakli S.1 Laboratory testing properties of sandstones Bulletin of the Geological Sociely of Greece, Vol. XXXX, Proc. $11^{\text {th }}$ Int. Congress, Athens, (2007).

16. Akram M. and Bakar M.Z.A. Correlation between uniaxial compressive strength and point load index for salt-range rocks. Pakistani Journal of Engineering and Applied Sciences; 1: 1e8 (2007).

17. Elkateb T. The point load test in the Persian Gulf carbonate rocks. Proc. $17^{\text {th }}$ Int. Conf. on Soil Mechanics and Geotechnical Engineering, 1;.372e5. (2009).

18. Singh T.N., Kainthola A and Venkatesh A. Correlation between point load index and uniaxial compressive strength for different rock types. Rock Mechanics and Rock Engineering; 45(2) 259 e64. (2012).

19. Salah H, Omar M, Shanableh A. Estimating unconfined compressive strength of sedimentary rocks in United Arab Emirates from point load strength index. Journal of Applied Mathematics and Physics; 2: 296 e303 (2014).

20. Khairalla, M. K., Study of the Nubian Sandstone Formation of the Nile Valley between the $14 \mathrm{~N}$ and $1742 \mathrm{~N}$ with reference to the ground water geology. M. Sc. thesis, U of K, 283pp, (1966)

21. Yousif, H. O. "Geotechnical Properties of the Nubian Mudstone and Weak Sandstone" M. Sc. Thesis, Building and Road Research Institute, University of Khartoum, Sudan, (1985)

22. International Society for Rock Mechanics (ISRM) (1985) Suggested Method for Determining Point Load Strength, ISRM Committee on Laboratory and Field Tests, Int. Jour. of Rock Mech, Min. Sci. \& Geomech., 22 (2): 53-60.

23. ASTM D6473-15 "Standard Test Method for Specific Gravity and Absorption of Rock For Erosion Control"

24. Elsharief A. M., Zein A. K. M. Elarabi H. and Abulgasim R. "Design practice of bored piles in Nubian formation" Sudan Engineering Society Journal, March, Volume 60; No.1, (2014).

25. Idris MA, Saiang D, Nordlund E. Numerical analyses of the effects of rock Mass property variability on open stope stability. In: The $45^{\text {th }} U S$ rock mechanics/geomechanics symposium, San Francisco, USA., AMRA, pp 1530e40 (2011). 